\title{
28 Research Suare \\ Cd5+ Diffuse Large B Cell Lymphoma of the Liver Presenting as Cholestatic Transaminitis.
}

Taroob Jawad Latef ( $\square$ taroobjlatef@gmail.com )

Baystate Medical Center https://orcid.org/0000-0002-4729-593X

Muhammad Bilal

Baystate Medical Center

Sudeep Siddappa Malleshappa

Baystate Medical Center

Chandravathi Loke

Baystate Medical Center

\section{Research Article}

Keywords: CD5+ DLBCL, HLH, EBV

Posted Date: July 27th, 2021

DOI: https://doi.org/10.21203/rs.3.rs-580354/v1

License: (9) This work is licensed under a Creative Commons Attribution 4.0 International License. Read Full License 


\section{Abstract}

A 72-year-old male with nonspecific symptoms was found to have pancytopenia and transaminitis. The pancytopenia began to improve early in the hospital course without specific treatment. A liver biopsy, obtained later to determine the etiology of the transaminitis, eventually confirmed CD5+ diffuse large $B$ cell lymphoma (DLBCL).

DLBCL typically presents with painless lymphadenopathy and constitutional symptoms although it may also present as a rapidly enlarging mass in any part of the body. However, in rarer cases its presentation can be misleading. Conditions such as HLH or viral infections, can confound a patient's presentation and delay the diagnosis. High index of suspicion is warranted for the diagnosis of DLBCL in atypical cases to prevent mortality associated with late diagnosis. Early recognition and biopsy of involved organ, in the absence of clear etiology, is vital for timely diagnosis and prompt treatment to achieve a favorable cure rate. CD5+ DLBCL may have unusual involvement of extra nodal organs such as the liver and may need further investigations.

\section{Background}

DLBCL is the most common lymphoma, constituting $25-35 \%$ of all cases of non-Hodgkin's lymphomas (NHL) in U.S.A. and Europe [1], and as much as $60 \%$ of these cases will have advanced stage (stage III/IV) DLBCL at the time of diagnosis accounting for an aggressive clinical course [2]. 5-10\% of DLBCL have been found to have CD5 expression [3].

Atypical presentations of various diseases provide important education experiences but may come at the cost of timely diagnosis. DLBCL is a malignancy in which prompt diagnosis and early treatment is crucial to decrease mortality. Furthermore, CD5+ DLBCL have been associated with an aggressive clinical course because of presence of anti-apoptotic properties that maintain B-cell survival. We report an anomalous presentation of CD5+ DLBCL which may promote awareness regarding early biopsy of involved organ in the absence of clear etiology to prevent delay in diagnosis.

\section{Case Presentation}

A 72-year-old Caucasian male with no significant past medical history presented with upper respiratory symptoms and was found to have pancytopenia and transaminitis, as detailed in table 1. Computed tomography of the abdomen and pelvis with contrast showed splenomegaly measuring $18.5 \mathrm{~cm}$ without lymphadenopathy or liver enlargement. Infectious work-up including blood cultures, enhanced respiratory PCR panel, COVID-19 RT-PCR, Lyme panel and PCR for Anaplasma, Babesia and Ehrlichia were negative. Peripheral smear did not show immature cells or inclusion bodies and was otherwise unremarkable. EBV and cytomegalovirus PCR were sent to evaluate for an alternative viral cause.

\section{Investigations}


Table 1. Laboratory results on day 1 , day 6 and day 12 of hospitalization.

\begin{tabular}{|c|c|c|c|}
\hline Laboratory Values & Day 1 & Day 6 & Day 12 \\
\hline White blood cells $\left(\mathrm{k} / \mathrm{mm}^{3}\right)$ & 1.6 & 2.2 & 3.0 \\
\hline Red blood cells $\left(\mathrm{m} / \mathrm{mm}^{3}\right)$ & 3.79 & 3.43 & 3.65 \\
\hline Hemoglobin $(\mathrm{gm} / \mathrm{dl})$ & 10.8 & 9.6 & 10.4 \\
\hline Hematocrit (\%) & 32.2 & 30.3 & 32.5 \\
\hline Platelets $\left(\mathrm{k} / \mathrm{mm}^{3}\right)$ & 32000 & 41000 & 87000 \\
\hline $\begin{array}{l}\text { Lactate dehydrogenase } \\
\text { (units/L) }\end{array}$ & 690 & 556 & 473 \\
\hline Haptoglobin (mg/dl) & - & 26 & - \\
\hline $\begin{array}{l}\text { Alkaline Phosphatase } \\
\text { (units/L) }\end{array}$ & 512 & 686 & 898 \\
\hline AST (units/L) & 192 & 197 & 104 \\
\hline$A L T$ (units $/ L$ ) & 244 & 260 & 150 \\
\hline Ferritin $(n g / m l)$ & 5473 & 7255 & 6799 \\
\hline$C R P(m g / d l)$ & 3.5 & - & 0.9 \\
\hline INR & 1.1 & 1.2 & 1.1 \\
\hline Total bilirubin (mg/dl) & 3.6 & 5.6 & 7.4 \\
\hline Direct bilirubin (mg/dl) & 3.0 & 5.0 & 6.2 \\
\hline Indirect bilirubin (mg/dl) & 0.6 & 0.6 & 1.2 \\
\hline Vitamin B12 (pg/ml) & - & 861 & - \\
\hline Folic acid $(\mathrm{ng} / \mathrm{ml})$ & - & 11.7 & - \\
\hline Hepatitis C antibody & - & Negative & - \\
\hline Hepatitis B surface antigen & - & Negative & - \\
\hline Hepatitis B core antibody & - & Negative & - \\
\hline Parvovirus B19 lgG & - & $1.8^{\wedge}$ & - \\
\hline Parvovirus B19 lgM & - & $0.1^{\wedge}$ & - \\
\hline Parvovirus B19 DNA PCR & - & - & Not detected \\
\hline CMV quant (IU/ml) & - & - & Not detected \\
\hline EBV viral capsid antibody IgM & - & $-<36 *$ & - \\
\hline
\end{tabular}




\begin{tabular}{|c|c|c|}
\hline EBV viral capsid antibody IgG & $162^{*}$ & - \\
\hline EBV nuclear antigen antibody & $<18^{*}$ & - \\
\hline EBV early antigen IgG & $11.5^{\star}$ & - \\
\hline EBV PCR quant (copies/ml) & - & Positive, $<100$ \\
\hline $\begin{array}{l}\text { Direct antiglobulin test anti- } \\
\text { lgG }\end{array}$ & Negative & - \\
\hline $\begin{array}{l}\text { Direct antiglobulin test anti- } \\
\text { C3b }\end{array}$ & $\begin{array}{l}\text { Negative } \\
319\end{array}$ & - \\
\hline $\begin{array}{l}\text { Triglycerides ((mg/dl) } \\
\text { IL2 soluble receptor }(\mathrm{pg} / \mathrm{ml})\end{array}$ & - & $\begin{array}{l}\text { Unable to interpret due to an interfering } \\
\text { substance }\end{array}$ \\
\hline $\begin{array}{l}\text { ALT, aspartate aminotransferas } \\
\text { international normalized ratio. }\end{array}$ & ALT, alanine aminotr & nsferase. CRP, C-reactive protein. INR, \\
\hline
\end{tabular}

The patient's mixed pattern of transaminitis and direct hyperbilirubinemia without evidence of biliary obstruction on ultrasound imaging was concerning for infiltrating phenomenon such as granulomatous liver disease, amyloidosis, tuberculosis and neoplastic infiltration of the liver and spleen. A liver biopsy was initially deferred due to presence of thrombocytopenia and high risk of bleeding. Other studies obtained ruled out nutritional deficiencies, microangiopathic hemolytic anemia and consumption coagulopathy. HLH was considered because of subjective fevers, elevated ferritin and triglyceride levels, splenomegaly and pancytopenia but IL2 soluble receptor results were equivocal due to the presence of an interfering substance. EBV PCR returned positive suggestive of a viral process although at $<100$ copies/ml, this was confirmatory.

The patient's pancytopenia began to improve spontaneously. However, the transaminitis gradually shifted from a mixed with predominantly hepatocellular pattern to an obstructive pattern and a liver biopsy was pursued. Ultrasound-guided core biopsy of the right hepatic lobe showed large B cells with co-expression of CD5, CD20, BCL-2, BCL 6, MUM1, PAX5 consistent with large B-cell lymphoma, non-germinal center type. Intravascular or intra-sinusoidal infiltration was not observed. FISH studies for c-MYC, BCL2, BCL6 were negative.

\section{OUTCOME AND FOLLOW-UP}

The patient was followed-up in outpatient oncology office where a bone marrow biopsy returned negative for large B-cell lymphoma. Positron emission tomography combined with CT (PET/CT) with fluorine-182-fluoro-2-deoxy- $d$-glucose (18F-FDG) scan showed a $1.8 \mathrm{~cm}$ area of uptake in the liver, as shown in figure 1 , and multiple sites of uptake in the skeleton. No evidence of nodal involvement was present. The 
patient was initiated on 6 cycles of R-CHOP $\times 6$ with high dose methotrexate for high-risk international prognostic index (IPI) and CNS IPI. The patient is currently on treatment while this case is being reported and doing well.

\section{Discussion}

CD5 is a glycoprotein that is typically present on the membranes of mature $T$ cells and is rarely expressed on $B$ cells. CD5 positive (CD5+) DLBCL was recognized as an immunophenotypic subset of DLBCL in the 2008 WHO classification but was eventually removed from the revised 2016 classification. However, the clinical significance of CD5+ DLBCL continues to be a topic of discussion [3].

De novo CD $5+$ DLBCL is rare and accounts for 5 to $22 \%$ of all DLBCL. It has an inferior survival rate with 5 -year overall survival of only 35\% compared to CD5 negative (CD5-) DLBCL. Despite being rare it has distinct clinical features of predilection for elderly, female population, elevated LDH, extra-nodal involvement, bone marrow involvement of $28 \%$ and CNS involvement at $13 \%$ with $40 \%$ belonging to high IPI risk group. Majority of CD5+ DLBCL belongs to ABC/non-GCB subtype. Co-expression of BCL-2 and MYC is found in $27 \%$ of CD5+ DLBCL whereas its only found in $3 \%$ of CD5- DLBCL.

DLBCL is further categorized into molecular subtypes; germinal center-B-cell-like (GCB) and activated Bcell-like (also known as non-GCB). EBV is a less common cause of non-GCB type DLBCL and has been associated with EBV-positive DLBCL of the elderly along with 5 to $10 \%$ of DLBCL not otherwise specified [4]. These infections can set off immune cascades in the body triggering sporadic cases of secondary HLH [5]. HLH is a life-threatening disorder of immune activation known to be caused by hematologic malignancies, most commonly NK/T-cell lymphomas [6] however it can be uncommonly associated with non-Hodgkin's B-cell lymphomas [7]. Hence, adults with suspected or diagnosed HLH should undergo a work-up for occult lymphomas [8].

Our patient described above scored 170 on the HScore, a diagnostic score for reactive hemophagocytic syndrome, indicative of $40-54 \%$ probability of hemophagocytic syndrome. A score of 169 is considered the best cutoff value with a sensitivity of $93 \%$ and a specificity of $86 \%$ [9].

Morphologically CD5+ DLBCL often shows intravascular or intra-sinusoidal filtration pattern. However, our patient's clinical presentation is somewhat unusual with lack of lymphadenopathy or mass lesions in the liver, predominantly portal pattern of infiltration and absence of bone marrow involvement. Persistent abnormalities in liver function tests prompted further work-up with biopsy that led to earlier diagnosis of DLBCL with the initiation of timely chemotherapy. The patient had resolution of pancytopenia, regression of splenomegaly and normalization of liver function within 2 weeks of discharge, prior to initiation of chemotherapy. This is suggestive of a possibility of DLBCL associated HLH or a viral insult such as EBV triggering the initial presentation, although serology was not conclusive.

\section{Conclusion}


Patients with atypical presentations of DLBCL and aberrant associated conditions such as HLH may prove to be a diagnostic challenge. Early recognition and biopsy of involved organ, in the absence of clear etiology, is vital for timely diagnosis and prompt treatment to achieve a favorable cure rate. CD5+ DLBCL may have unusual involvement of extra nodal organs such as the liver and may need further investigations.

\section{Declarations}

Funding: No funding was received for the submission of this manuscript.

Conflicts of interest/Competing interests: I and all the other authors have no conflicts of interest to declare that are relevant to the content of this article. The authors have no relevant financial or nonfinancial interests to declare. We declare that the manuscript is original, has not been published or presented before and is not being considered for publication elsewhere. As the corresponding author, I confirm that the manuscript has been read and approved for submission by all the listed authors.

\section{Availability of data and material: Not applicable}

Ethics approval: All ethical requirements were complied with during the writing of this manuscript. The manuscript is in accordance with the ethical standards of our institution. Informed consent was obtained from the patient. The contents of the manuscript were discussed in detail with the patient.

Authors' contributions: All authors contributed to the study conception and design. Material preparation, data collection and analysis were performed by Taroob Latef, Muhammad Bilal, Sudeep Mallehsappa and Chandravathi Loke. The first draft of the manuscript was written by Taroob Latef and all authors commented on previous versions of the manuscript. All authors read and approved the final manuscript.

Consent to participate: Informed consent was obtained from the patient and the contents of the manuscript were discussed in detail with the patient.

Consent for publication: The participant has consented to the submission of the case report to the journal for publication.

\section{References}

1. Morton LM, Wang SS, Devesa SS, Hartge P, Weisenburger DD, Linet MS. Lymphoma incidence patterns by WHO subtype in the United States, 1992-2001. Blood. 2006 Jan 1;107(1):265-76. doi: 10.1182/blood-2005-06-2508. Epub 2005 Sep 8.

2. Armitage JO, Weisenburger DD. New approach to classifying non-Hodgkin's lymphomas: clinical features of the major histologic subtypes. Non-Hodgkin's Lymphoma Classification Project. J Clin Oncol. 1998 Aug;16(8):2780-95. 
3. Na HY, Choe JY, Shin SA, et al. Characteristics of CD 5-positive diffuse large B-cell lymphoma among Koreans: High incidence of BCL2 and MYC double-expressors. PLoS One. 2019;14(10):e0224247. Published 2019 Oct 23. doi:10.1371/journal.pone.0224247

4. Shannon-Lowe C, Rickinson AB, Bell Al. Epstein-Barr virus-associated lymphomas. Philos Trans $R$ Soc Lond B Biol Sci. 2017;372(1732):20160271.

5. Malkan UY, Albayrak M, Yildiz A, Maral S, Afacan Ozturk HB, Comert P. A rare case of diffuse large Bcell lymphoma-associated hemophagocytic lymphohistiocytosis. Journal of Oncology Pharmacy Practice. 2021;27(1):250-252.

6. Miyahara M, Sano M, Shibata K, et al. B-cell lymphoma-associated hemophagocytic syndrome: clinicopathological characteristics. Ann Hematol 2000; 79: 378.

7. Wu R, Deng X, Hao S, Ma L. Successful treatment of diffuse large B-cell lymphoma with secondary hemophagocytic lymphohistiocytosis by R-CHOP-E regimen: a case report. Journal of International Medical Research. February 2020.

8. Geiger, K. et al. "Hemophagocytic Lymphohistiocytosis as the Presenting Symptom of Aggressive Lymphoma - A Case Series and Review of the Literature: NHL-033." Clinical Lymphoma, Myeloma \& Leukemia 18 (2018): S271.

9. Fardet L, Galicier L, Lambotte O, Marzac C, Aumont C, Chahwan D, Coppo P, Hejblum G. Development and validation of the HScore, a score for the diagnosis of reactive hemophagocytic syndrome. Arthritis Rheumatol. 2014 Sep;66(9):2613-20.

\section{Figures}




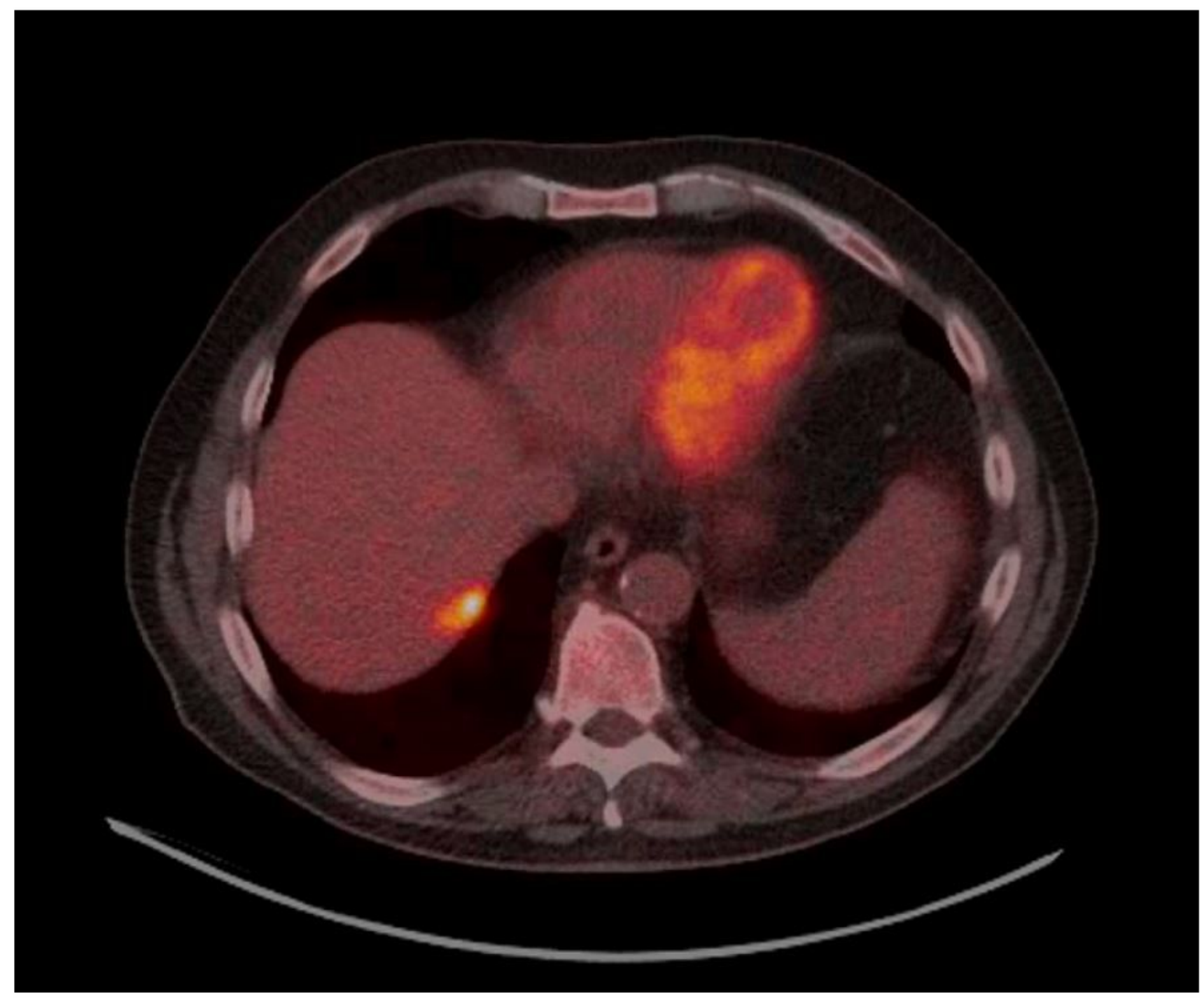

Figure 1

PET/CT with 18F-FDG scan showing FDG avid liver lesion. 